OPEN ACCESS

Vol. 2 No. 1: 14-21

Tahun 2018

Artikel penelitian 圆
Jurral Alinatiklestari

E-ISSN: 2598-8204

https://ojs.umrah.ac.id/index.php/akuatiklestari

DOI : https://doi.org/10.31629/akuatiklestari.v2i1.2348

\title{
Potensi Sumberdaya Lamun sebagai Pencadangan Kawasan Konservasi di Perairan Beloreng, Tembeling, Kabupaten Bintan
}

\author{
Seagrass Resource Potential as A Reservator Conservation Area in Beloreng Waters, Tembeling, \\ Bintan Regency
}

\section{Puput Ika Pratiwi $^{1}$, Febrianti Lestari ${ }^{1}$, Susiana $^{1}$}

${ }^{1}$ Manajemen Sumberdaya Perairan, Fakultas Ilmu Kelautan dan Perikanan, Universitas Maritim Raja Ali Haji, Tanjungpinang, Indonesia 29111

\section{$\square$ Info Artikel:}

Diterima: 10 Agustus 2018

Revisi: 25 Agustus 2018

Disetujui: 1 Oktober 2018

Dipublikasi: 20 November 2018

\section{[1] Keyword:}

Lamun, Pencadangan Kawasan

Konservasi, Bintan, Perairan Beloreng

\begin{abstract}
ABSTRAK. Penelitian mengenai potensi sumberdaya lamun sebagai pencadangan kawasan konservasi telah dilakukan di Perairan Beloreng, Tembeling, Kabupaten Bintan. Tujuan penelitian ini adalah mengetahui potensi ekologi sumberdaya lamun, mengetahui jenis biota yang berasosiasi di padang lamun, dan mengetahui tingkat kesesuaian sumberdaya lamun sebagai pencadangan kawasan konservasi di Perairan Beloreng, Tembeling, Kabupaten Bintan. Penelitian ini dilakukan dengan metode acak sebanyak 31 titik menggunakan plot berukuran $0,5 \times 0,5$ meter. Hasil penelitian ditemukan 5 jenis lamun yaitu, Enhalus acoroides, Thalassia hemprichii, Cymodocea serrulata, Halodule uninervis, dan Halophila decipiens. Jenis biota yang dijumpai diantaranya kepiting rajungan (Portunus pelagicus), kerang kampak (Atrina pectinata), siput gonggong (Strombus turturella), ikan baronang (Siganus sp.), teripang jepun (Stichopus chloramatus), dugong (Dugong dugon) dan ular (Bungarus fasciatus). Tingkat kesesuaian sumberdaya lamun dilihat dari aspek ekologi, sosial dan budaya tergolong dalam kategori S2 (sesuai bersyarat) untuk dijadikan pencadangan kawasan konservasi lamun.
\end{abstract}

\section{凰 How to cite this article:}

Putri, P.I., Lestari, F., \& Susiana. (2018). Potensi Sumberdaya Lamun sebagai Pencadangan Kawasan Konservasi di Perairan Beloreng, Tembeling, Kabupaten Bintan. Jurnal Akuatiklestari, 2(1): 14-21. https://doi.org/10.31629/akuatiklestari.v2i1.2348

\section{PENDAHULUAN}

Ekosistem padang lamun merupakan salah satu ekosistem yang terdapat di daerah pesisir (Purba et al., 2018; Sari et al., 2018). Padang lamun merupakan ekosistem yang terdiri dari satu atau lebih spesies lamun yang berinteraksi dengan faktor biotik dan abiotik di lingkungannya (Purnomo et al., 2017). Lamun mempunyai fungsi sebagai produsen primer, stabilator dasar perairan, pendaur hara, sumber makanan dan tempat asuhan (Azkab, 2000).

Ekosistem lamun merupakan salah satu ekosistem yang dapat dikembangkan melalui kegiatan konservasi. Menurut Syukur (2016), upaya konservasi lamun berkaitan dengan fungsi perlindungan dan pelestarian keragaman dan kekayaan spesies ikan Selain itu untuk keberlanjutan produktivitas perikanan pesisir dan keamanan pangan.

Di Indonesia terdapat 13 jenis lamun yang tersebar hampir diseluruh perairan Indonesia, dengan perkiraan luas $\pm 30.000 \mathrm{~km}^{2}$ (Kuo, 2007). Provinsi Kepulauan Riau memiliki potensi lamun yang cukup luas salah satunya di Kabupaten Bintan. Kabupaten Bintan terdapat 11 jenis lamun yang memiliki luasan padang lamun $\pm 2.500 \mathrm{Ha}$ (Bappeda Kabupaten 
Bintan, 2010). Perairan yang memiliki potensi lamun yang cukup luas adalah Perairan Beloreng yang terdapat di Kampung Beloreng, Kelurahan Tembeling Tanjung, Kecamatan Teluk Bintan, Kabupaten Bintan.

Perairan Beloreng memiliki lamun yang cukup luas dan dimanfaatkan oleh nelayan setempat untuk mencari ikan dan biota laut lainnya yang bernilai ekonomis. Dengan potensi kawasan lamun yang cukup luas dan menjadi habitat vital bagi biota perairan seperti gonggong dan biota dilindungi seperti dugong. Maka keberadaan ekosistem padang lamun di Perairan Beloreng perlu upaya perlindungan dengan konservasi. Oleh karena itu, perlu dilakukannya penelitian tentang Potensi Sumberdaya Lamun sebagai Pencadangan Kawasan Konservasi di Perairan Beloreng, Tembeling, Kabupaten Bintan. Tujuan penelitian ini adalah mengetahui potensi ekologi sumberdaya lamun, mengetahui jenis biota yang berasosiasi di padang lamun, dan mengetahui tingkat kesesuaian sumberdaya lamun sebagai pencadangan kawasan konservasi di Perairan Beloreng, Tembeling, Kabupaten Bintan.

\section{BAHAN DAN METODE}

\subsection{Waktu dan Tempat}

Penelitian ini dilaksanakan pada bulan April-Juli 2018 di Perairan Beloreng, Kelurahan Tembeling Tanjung, Kecamatan Teluk Bintan, Kabupaten Bintan. Adapun lokasi penelitian dapat dilihat pada Gambar 1.

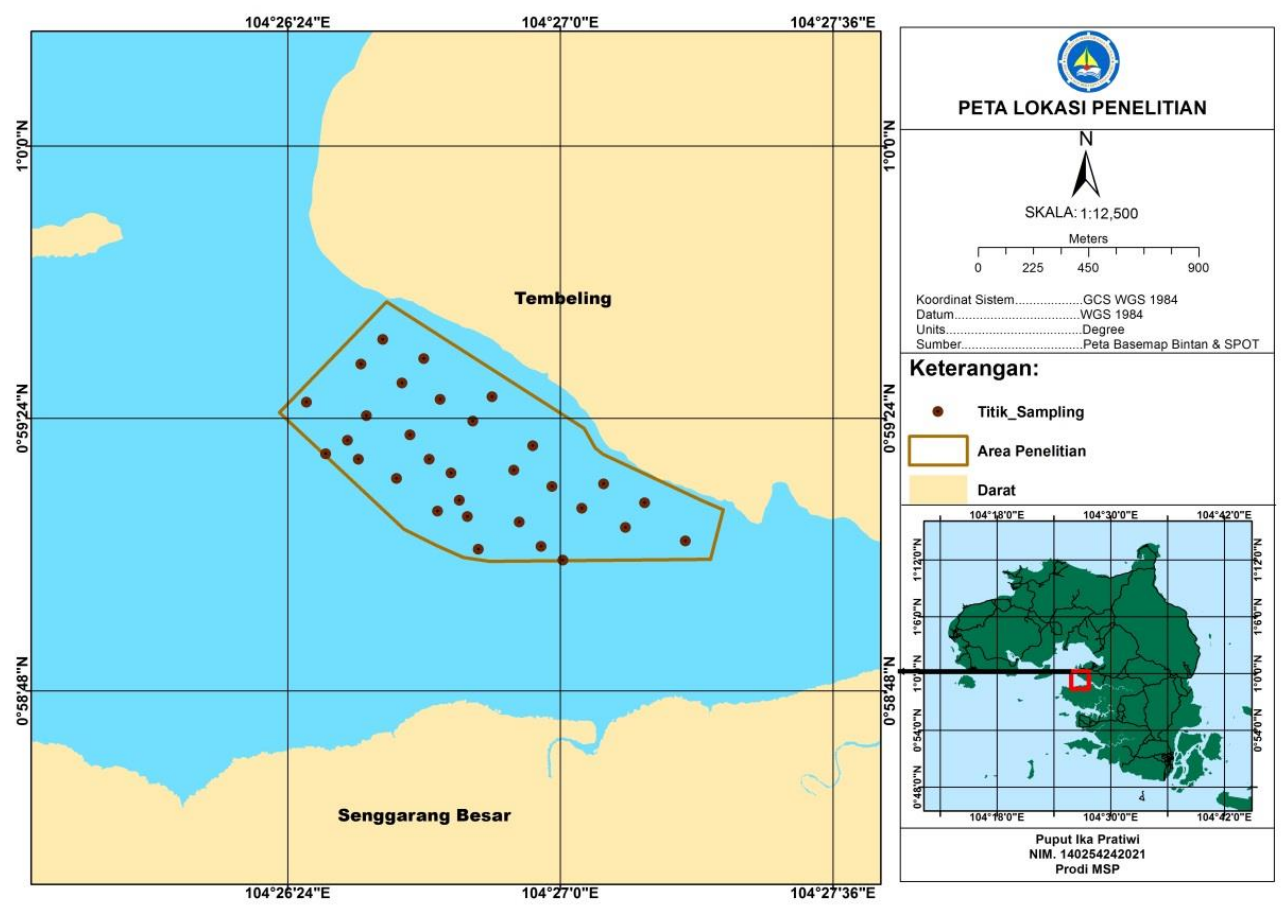

Gambar 1. Peta lokasi penelitian

\subsection{Alat dan Bahan}

Alat yang digunakan antara lain adalah recorder untuk merekam, kamera untuk dokumentasi, alat tulis untuk mencatat data penelitian, GPS untuk menunjukkan lokasi penelitian, gill net untuk jaring menangkap ikan, petak contoh ukuran 0,5 m x $0.5 \mathrm{~m}$ untuk pengukuran data lamun dan petak contoh $1 \mathrm{~m}$ x $1 \mathrm{~m}$ untuk pengambilan data biota.

\subsection{Prosedur Penelitian}

\subsubsection{Penentuan Stasiun Pengamatan}

Stasiun penelitian ditentukan dengan cara observasi awal lapangan. Penentuan stasiun berdasarkan kebutuhan informasi yang diinginkan yaitu kawasan perairan yang ditumbuhi lamun. Stasiun pengamatan ditentukan menggunakan metode Random sampling (pengambilan sampel secara acak) (Raharja,2008). Jumlah total titik sampel yang digunakan pada penelitian ini berjumlah 31 titik yang menyebar disepanjang Perairan Beloreng, Kelurahan Tembeling Tanjung, Kecamatan Teluk Bintan, Kabupaten Bintan.

\subsubsection{Metode Sampling Lamun}

Pengambilan sampel lamun menggunakan petak contoh mengacu pada Kepmen LH Nomor 200 Tahun 2004. Pengambilan lamun menggunakan transek kuadran berukuran $50 \mathrm{~cm}$ x $50 \mathrm{~cm}$ yang terdiri dari 25 sub petak yang berukuran $10 \mathrm{~cm}$ x $10 \mathrm{~cm}$ (Gambar 2). Kemudian catat banyaknya masing-masing jenis lamun pada tiap sub petak lalu hitung kerapatan jenisnya. 


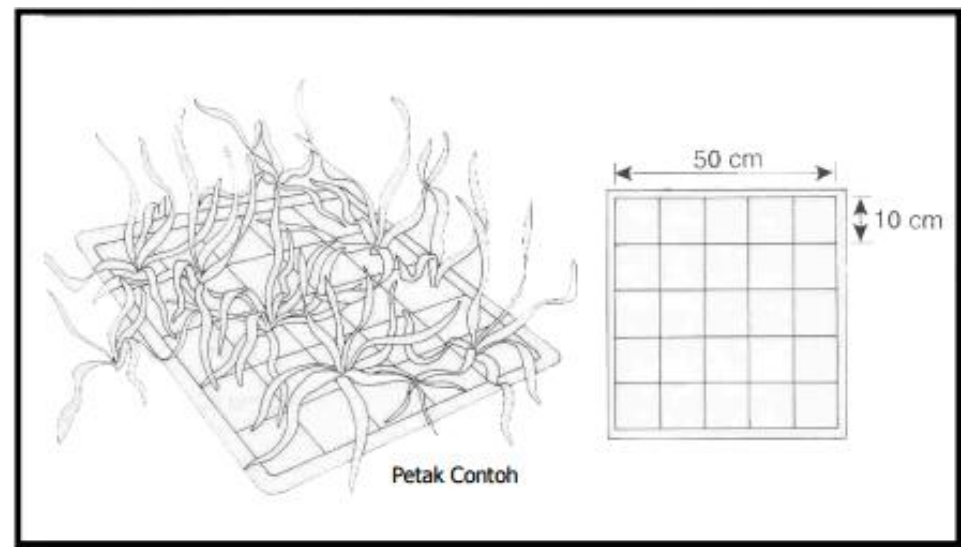

Gambar 2. Petak Contoh (sumber: Kepmen LH nomor 200 tahun 2004)

Persentase penutupan lamun ditentukan dengan metode (Saito \& Atobe, 1970). Petak contoh yang digunakan untuk pengambilan contoh berukuran $50 \mathrm{~cm}$ x $50 \mathrm{~cm}$ yang masih dibagi-bagi lagi menjadi 25 subpetak dengan ukuran $10 \mathrm{~cm} \times 10 \mathrm{~cm}$

\subsubsection{Metode Sampling Biota}

Pengambilan sampel biota menggunakan transek $1 \mathrm{~m}$ x $1 \mathrm{~m}$. Metode pengamatan biota ini dilakukan bertujuan mengidentifikasi biota yang berasosisai di kawasan ekosistem lamun di Perairan Beloreng, Tembeling, Kabupaten Bintan. Metode yang digunakan untuk melakukan pengamatan terhadap biota makrozobentos ialah observasi langsung dengan cara manual biota diambil menggunakan tangan pada petak contoh dengan ukuran $1 \mathrm{~m} x \mathrm{~m}$. Untuk pengambilan data ikan dan udang dikumpulkan dengan menggunakan alat tangkap gill net. Lokasi penangkapan ditetapkan pada tiap stasiun. Penarikan alat tangkap (setting hauling) dilakukan pada saat air pasang menjelang surut, gill net dipasang pada saat air akan pasang dan hasilnya dikumpulkan pada saat setelah air surut. Mengidentifikasi nekton menggunakan data primer dan sekunder, untuk data primer didapatkan dari observasi langsung ke lapangan dengan alat tertentu dalam pengambilan sampel nekton yang bergerak, sedangkan untuk data sekunder diambil dari wawancara terhadap nelayan setempat.

\subsubsection{Teknik Pengambilan Responden}

Teknik pengambilan sampel adalah menggunakan teknik Random sampling. Menggunakan pemilihan random untuk memastikan bahwa tiap elemen populasi mempunyai peluang yang sama dalam pemilihan. Tabel bilangan acak dapat dipakai untuk mecapai keacakan (randomness) (Raharja, 2008). Pengambilan sampel responden pada masyarakat yang melakukan aktivitas sekitar perairan beloreng adalah sebesar 30 responden.

\subsection{Teknik Pengumpulan Data}

Teknik pengumpulan data menggunakan data primer dan data sekunder. Pengumpulan data primer dilakukan melalui pengamatan langsung (observasi) di lapangan, dengan melakukan pengukuran potensi ekosistem lamun dan melakukan wawancara langsung dengan pengunjung, masyarakat lokal dan pihak-pihak terkait. Pengumpulan data sekunder dilakukan dengan cara mengumpulkan dokumen-dokumen hasil studi/penelitian, peraturan perundangundangan dan data pendukung lainnya dan juga dapat dikumpulkan melalui studi pustaka meliputi keadaan umum kawasan, potensi sumberdaya lamun untuk kegiatan konservasi serta keadaan sosial masyarakat.

\subsection{Analisis Data}

\section{Kerapatan Jenis Lamun}

Kerapatan jenis lamun yaitu jumlah total individu suatu jenis lamun dalam unit area yang diukur. Kerapatan jenis lamun ditentukan berdasarkan rumus Hardiyanti et al. (2011). Kriteria kondisi kerapatan jenis lamun menurut Gosari \& Haris (2012) disajikan pada Tabel $\mathbf{l}$.

$$
D i=\frac{\mathrm{ni}}{\mathrm{A}}
$$

Keterangan :

Di : Kerapatan Jenis (ind $/ \mathrm{m}^{2}$ )

ni : Jumlah total tegakan spesies (tegakan)

A : Luas total pengambilan sampel $\left(\mathrm{m}^{2}\right)$ 
Tabel 1. Skala Kondisi Kerapatan Jenis Lamun (Gosari \& Haris, 2012)

\begin{tabular}{ccc} 
Tingkatan & Kerapatan(ind $\left./ \mathbf{m}^{\mathbf{2}}\right)$ & Kriteria \\
5 & $>175$ & Sangat rapat \\
4 & $125-175$ & Rapat \\
3 & $75-125$ & Agak rapat \\
2 & $25-75$ & Jarang \\
1 & $<25$ & Sangat jarang \\
\hline
\end{tabular}

\section{Indeks Keanekaragaman Jenis}

Keanekaragaman spesies dapat dikatakan sebagai keheterogenan spesies dan merupakan ciri khas struktur komunitas. Rumus yang digunakan untuk menghitung keanekaragaman adalah rumus Shannon-Wiener (Krebs, 1985) yaitu:

$$
H^{\prime}=-\sum\left(\frac{n i}{N}\right) x \log \left(\frac{n i}{N}\right)
$$

Keterangan:

$\begin{array}{ll}\mathrm{H}^{\prime} & =\text { lndeks Keanekaragaman } \\ \mathrm{N} & =\text { Jumlah total individu semua spesies } \\ \mathrm{ni} & =\text { Jumlah individu jenis ke-i }\end{array}$

Kisaran nilai indeks keanekaragaman Shannon ditentukan berdasarkan kriteria sebagai berikut:

- Jika nilai $\mathrm{H}<1$ maka nilai indeks keanekaragaman rendah,

- Jika $\mathrm{l}<\mathrm{H}<3$ maka nilai indeks keanekaragaman sedang, dan

- Jika $\mathrm{H}>3$ maka nilai indeks keanekaragaman tinggi.

\section{Analisisa Data Kesesuaian Konservasi}

Analisis data bertujuan untuk menyederhanakan data ke dalam bentuk yang lebih mudah di pahami dan diinterpretasikan. Data yang dikumpulkan meliputi : jenis lamun, identifikasi biota yang berasosiasi lamun, kerapatan jenis lamun, dan data dari wawancara masyarakat.

Untuk menentukan daerah tersebut masuk dalam kategori sesuai untuk kawasan konservasi maka digunakan rumus sebagai berikut (modifikasi Yulianda, 2007):

$$
I K K L=\sum\left(\frac{n i}{N m a k s}\right) \times 100 \%
$$

Keterangan :

IKKL : Indeks kesesuaian konservasi lamun

ni : Nilai parametr ke-i (bobot x skor)

Nmaks : Nilai maksimun dari suatu kategori

Penentuan kesesuaian berdasarkan perkalian skor dan bobot yang diperoleh dari setiap parameter. Kesesuaian kawasan dilihat dari tingkat persentase kesesuaian yang diperoleh dari penjumlah nilai dari seluruh parameter pada Tabel 2.

\begin{tabular}{|c|c|c|c|c|}
\hline \multirow[b]{2}{*}{ Kriteria Penetapan Kawasan Konservasi } & \multirow[b]{2}{*}{ Bobot } & \multicolumn{3}{|c|}{ Skor } \\
\hline & & $\begin{array}{c}\text { Sangat Sesuai } \\
\text { (3) }\end{array}$ & $\begin{array}{l}\text { Sesuai } \\
(2)\end{array}$ & $\begin{array}{c}\text { Kurang Sesuai } \\
\text { (1) }\end{array}$ \\
\hline - Indeks Keanekaragaman Jenis (H') & 4 & Tinggi & Sedang & Rendah \\
\hline - Keterkaitan Ekologis & 3 & $>75 \%$ & $50 \%-75 \%$ & $<50 \%$ \\
\hline - Keunikan (sebaran flora, fauna, ekosistem) & 2 & Unik & Cukup Unik & Tidak Unik \\
\hline - Daerah Ruaya (Jenis ikan) & 2 & $>1$ & 1 & 0 \\
\hline $\begin{array}{l}\text { - Habitat Ikan Khas/ Langka/ Unik/ Endemik Dan } \\
\text { Dilindungi (Jenis ikan) }\end{array}$ & 4 & $>2$ & $1-2$ & 0 \\
\hline - Daerah Pemijahan Ikan (Lokasi) & 3 & $>2$ & 2 & \\
\hline - Dukungan Masyarakat & 2 & $>75 \%$ & $40 \%-75 \%$ & $<40 \%$ \\
\hline - Potensi Konflik Kepentingan & 2 & Kurang & Sedang & Tinggi \\
\hline - Potensi Ancaman & 4 & $>5$ & $2-5$ & $<2$ \\
\hline - Kearifan Lokal & 1 & Efektif & Kurang Efektif & Tidak Efektif \\
\hline - Adat Istiadat & 1 & Efektif & Kurang Efektif & Tidak Efektif \\
\hline
\end{tabular}

Tabel 2. Matriks Penilaian Kesesuaian Kawasan Konservasi

Sumber : Data dan informasi kriteria pertimbangan dan penentuan dealinasi serta pengaturan kawasan konservasi dalam RZWP3K (KKP, 2013) 
Keterangan: (nilai maksimum = 84)

Sl = sangat sesuai, dengan nilai $85 \%-100 \%$

S2 = sesuai, dengan nilai $70 \%-85 \%$

S3 = sesuai bersyarat dengan nilai $55 \%-70 \%$

$\mathrm{N} \quad=$ tidak sesuai, dengan nilai $<55 \%$

\section{HASIL DAN PEMBAHASAN}

\subsection{Kondisi Umum Perairan Beloreng}

Secara geografis Perairan Beloreng terletak di Kampung Beloreng, Kelurahan Tembeling Tanjung, Kecamatan Teluk Bintan, Kabupaten Bintan. Dengan luas wilayah adalah 28,2 km². Secara administrasi adapun batas wilayah Kampung Beloreng adalah sebagai berikut:

Sebelah Utara : Berbatasan dengan Desa Tembeling

Sebelah Selatan : Berbatasan dengan Kelurahan Kampung Bugis Tanjungpinang

Sebelah Barat : Berbatasan dengan Desa Penaga

Sebelah Timur : Berbatasan dengan Kelurahan Toapaya Asri.

Perairan Beloreng adalah salah satu daerah estuari yang merupakan pencampuran antara air laut dan air tawar yang berasal dari sungai. Beberapa aktifitas warga yang dilakukan pada sekitaran Perairan Beloreng adalah menombak udang, menangkap ikan menggunakan jaring, memasang bubu kepiting dan mencari gonggong. Di Perairan Beloreng, masyarakat hanya dimanfaatkan untuk mencari ikan dan biota lainnya yang bernilai ekonomis

\subsection{Potensi Ekologi Sumberdaya Lamun di Perairan Beloreng}

\subsubsection{Jenis Lamun di Perairan Beloreng}

Hasil penelitian ditemukan 5 jenis lamun yaitu, Enhalus acoroides, Thalassia hemprichii, Cymodocea serrulata, Halodule uninervis, dan Halophila decipiens. Jenis dan klasifikasi lamun yang di temukan pada perairan Beloreng dapat dilihat pada Tabel 3.

Tabel 3. Jenis dan Klasifikasi Lamun yang Ditemukan pada Perairan Beloreng

\begin{tabular}{|c|c|c|}
\hline No & Gambar Lamun & Klasifikasi \\
\hline 1. & & $\begin{array}{ll}\text { Divisi } & \text { : Anthophyta, } \\
\text { Subkelas : Monocotyledoneae, } \\
\text { Ordo } & \text { : Helobiae, } \\
\text { Famili } & \text { : Hydrocharitaceae, } \\
\text { Genus } & \text { : Enhalus, } \\
\text { Spesies } & \text { : Enhalus acoroides }\end{array}$ \\
\hline 2. & & $\begin{array}{l}\text { Divisi : Anthophyta, } \\
\text { Subkelas : Monocotyledoneae, } \\
\text { Ordo : Helobiae, } \\
\text { Famili : Hydrocharitaceae, } \\
\text { Genus : Thalassia, } \\
\text { Spesies : Thalassia hemprichii }\end{array}$ \\
\hline 3. & & $\begin{array}{ll}\text { Divisi } & \text { : Anthophyta, } \\
\text { Subkelas : Monocotyledoneae, } & \\
\text { Ordo } & \text { : Helobiae, } \\
\text { Famili } & : \text { Cymodoceaceae, } \\
\text { Genus } & : \text { Cymodocea, } \\
\text { Spesies } & \text { : Cymodocea serrulata }\end{array}$ \\
\hline 4. & & $\begin{array}{l}\text { Divisi : Anthophyta, } \\
\text { Subkelas : Monocotyledoneae, } \\
\text { Ordo : Helobiae, } \\
\text { Famili } \quad \text { : Cymodoceaceae, } \\
\text { Genus } \quad \text { Halodule, } \\
\text { Spesies }\end{array}$ \\
\hline 5. & & $\begin{array}{ll}\text { Divisi } & \text { : Anthophyta, } \\
\text { Subkelas : Monocotyledoneae, } & \\
\text { Ordo } & \text { : Helobiae, } \\
\text { Famili } & \text { : Hydrocharitaceae, } \\
\text { Genus } & \text { : Halophila, } \\
\text { Spesies } & \text { : Halophila decipiens }\end{array}$ \\
\hline
\end{tabular}

Jenis Enhalus acoroides memiliki daun yang panjang dan berbentuk seperti pita. Bentuk rimpangnya tebal dengan rambut hitam panjang dan akar seperti tali. Serta memiliki panjang daun 30-150 cm (Rahmawati et al., 2014). Jenis lamun ini merupakan jenis lamun yang paling banyak ditemukan pada Perairan Beloreng. Jenis Thalassia hemprichii memiliki daun 
yang berbentuk sabit dengan bintik-bintik hitam kecil pada daunnya dan memiliki panjang daun $10-40 \mathrm{~cm}$. Bentuk rimpang tebal dengan skala diantara tunas. Jenis Cymodecea serulata memiliki daun yang ujungnya membulat dengan panjang daun 7-15 cm dan helai daunnya sempit (lebarnya 2-4 mm). Jenis Halodule uninervis memiliki daun yang ujungnya membentuk seperti trisula dengan satu pusat pembuluh daun dan umumnya rimpang pucat dan jenis lamun ini yang paling sedikit di jumpai. Dan jenis Halophila decipiens memiliki panjang helai daun 1-2,5 cm, memiliki rambut daun pada kedua sisi dan tepi daunnya bergerigi dan berbentuk oval.

\subsubsection{Kerapatan Jenis Lamun}

Hasil analisis kerapatan lamun di perairan Beloreng diketahui bahwa tingkat kerapatan lamun di perairan tersebut termasuk dalam kategori kerapatan yang jarang. Lebih lanjut dapat dilihat pada Tabel 4.

Tabel 4. Kerapatan jenis lamun di Perairan Beloreng

\begin{tabular}{clcc} 
No & \multicolumn{1}{c}{ Jenis } & Jumlah (tegakan) & Kerapatan Jenis (tegakan/ $\mathbf{m}^{\mathbf{2}}$ ) \\
1 & Thalassia hempricii & 717 & 93 \\
2 & Enhalus acoraides & 491 & 63 \\
3 & Cymodocea serrulata & 437 & 56 \\
4 & Halodule uninervis & 318 & 41 \\
5 & Halophila decipiens & 450 & 58 \\
& Jumlah & $\mathbf{2 4 1 3}$ & $\mathbf{3 1 1}$ \\
& Rata-rata & & $\mathbf{6 2 , 2 7}$ \\
\hline
\end{tabular}

Dari Tabel 4. diketahui jenis lamun yang memiliki jumlah tegakan tertinggi adalah jenis lamun Thalassia hemprichii (717 tegakan) sementara untuk nilai terendah adalah jenis lamun Halodule uninervis (318 tegakan). Kerapatan jenis lamun di Perairan Beloreng didapatkan dengan nilai rata-rata yaitu 62,27 tegakan/ $\mathrm{m}^{2}$. Nilai kerapatan jenis di lokasi penelitian $25-$ $75 \mathrm{ind} / \mathrm{m}^{2}$ atau jarang. Menurut Wagey \& Sake (2013), kerapatan lamun tertinggi jenis lamun Thalassia hemprichii, tumbuhan ini merupakan spesies lamun cepat tumbuh dan mampu berkolonisasi dengan cepat di daerah yang mengalami gangguan.

\subsubsection{Indeks Keanekaragaman Jenis ( $\left.\mathrm{H}^{\prime}\right)$}

Keanekaragaman adalah indeks yang digunakan untuk melihat kestabilan struktur komunitas lamun. Berdasarkan hasil penelitian, diperoleh keanekaragaman dengan nilai 0,68. Indeks keanekaragamannya ini termasuk kategori rendah. Menurut Syukur (2015), Padang lamun sebagai sumber keanekaraman hayati adalah aspek penting nilai keberadaan ekologi lamun. Semakin tinggi nilai indeks keanekaragaman menunjukkan semakin tinggi keberagaman jenis lamun yang ada. Namun pada lokasi penelitian ini tingkat keanekaragamannya rendah, di tunjukkan dari jumlah yang ditemukan hanya ada 5 jenis lamun.

\subsection{Jenis Biota yang Berasosiasi di Ekosistem Padang Lamun}

Hasil pengamatan di perairan Beloreng untuk jenis biota laut yang hidup dengan ekosistem padang lamun ditemukan sebanyak 7 jenis biota. Adapun deskripsi masing-masing jenis biota yang berasosiasi pada lamun di Perairan Beloreng dapat dijelaskan pada Tabel 5.

Tabel 5. Jenis Biota yang Berasosiasi di Ekosistem Padang Lamun pada Perairan Beloreng

\begin{tabular}{lll} 
No Gambar Biota & \multicolumn{1}{c}{ Klasifikasi } \\
Kelas : Crustacean, \\
Ordo : Eucaridae, \\
Famili : Portunidae, \\
Spesies : Portunus pelagicus. \\
Filum : Mollusca \\
Kelas : Bivalvia \\
Ordo : Mytiludea \\
Famili : Pinnidea \\
Genus : Atrina \\
Species : Atrina pectinata \\
\\
\\
\end{tabular}


4.

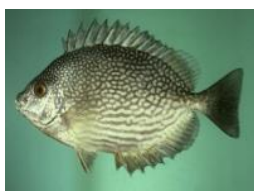

Filum : Chordata,

Kelas : Pisces,

ordo : Perciformes

famili : siganidae,

genus : Siganus,

spesies : Siganus sp.

5.

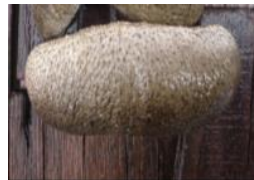

Filum : Echinodermata

Kelas : Holothuroidea

Ordo : Aspidochirotida

Famili : Holothuriidae

Genus : Stichopus

Species : Stichopus chloramatus

6.

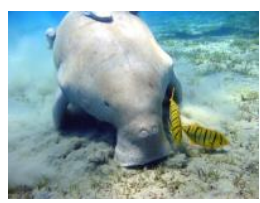

Filum : Chordata

Kelas : Mamalia

Ordo : Sirenia

Famili : Dugongidea

Genus : Dugong

Species : Dugong dugon

7.

Filum : Chordata

Kelas : Reptilia

Ordo : Squamata

Famili : Elapidea

Genus : Bungarus

Species : Bungarus fasciatus

\subsection{Analisis Kesesuaian Kawasan Konservasi Lamun}

Analisis kesesuaian kawasan konservasi lamun diukur berdasarkan beberapa parameter yaitu indeks keanekaragaman jenis, keterkaitan ekologis, keunikan, daerah ruaya, habitat ikan khas/langka/unik /endemik/dilindungi, daerah pemijahan ikan, dukungan masyarakat, potensi konflik kepentingan, potensi ancaman, kearifan local dan adat istiadat. Adapun hasil analisis kesesuaian kawasan konservasi lamun dapat dilihat pada Tabel 6.

Tabel 6. Analisis Kesesuaian Kawasan Konservasi Lamun

\begin{tabular}{|c|c|c|c|c|}
\hline Kriteria Penetapan Kawasan Konservasi & Bobot & Hasil & Skor & $\mathbf{N i}$ \\
\hline \multicolumn{5}{|l|}{ - $\quad$ Ekologi } \\
\hline Indeks Keanekaragaman Jenis ( $\left.\mathrm{H}^{\prime}\right)$ & 4 & 0.68 & 1 & 4 \\
\hline Keterkaitan Ekologis & 3 & $>75 \%$ & 3 & 9 \\
\hline Keunikan (sebaran flora, fauna, ekosistem) & 2 & Unik & 1 & 2 \\
\hline Daerah Ruaya (Jenis ikan) & 2 & 1 & 2 & 4 \\
\hline $\begin{array}{l}\text { Habitat Ikan Khas/ Langka/ Unik/ Endemik dan Dilindungi } \\
\text { (Jenis ikan) }\end{array}$ & 4 & 2 & 2 & 8 \\
\hline $\begin{array}{l}\text { Daerah Pemijahan Ikan (Lokasi) } \\
\text { - Sosial \& Budaya }\end{array}$ & 3 & 2 & 2 & 6 \\
\hline Dukungan Masyarakat & 2 & $<40 \%$ & 1 & 2 \\
\hline Potensi Konflik Kepentingan & 2 & Kurang & 3 & 6 \\
\hline Potensi Ancaman & 4 & $<2$ & 2 & 8 \\
\hline Kearifan Lokal & 1 & Efektif & 3 & 3 \\
\hline Adat Istiadat & 1 & Tidak Efektif & 1 & 1 \\
\hline Nilai maksimum analisis kesesuaian $=93$ & & & $\Sigma$ ni & 53 \\
\hline
\end{tabular}

Dari Tabel 6. menjelaskan bahwa nilai Indeks Kesesuian Kawasan Konservasi Lamun (IKKL) untuk konservasi lamun di kawasan Perairan Beloreng yang terdapat di Kampung Beloreng, Kelurahan Tembeling Tanjung, Kecamatan Teluk Bintan, Kabupaten Bintan yaitu 63\%. Berdasarakan tabel analisis kesesuaian dengan kriteria parameternya untuk konservasi lamun dikawasan tersebut termasuk dalam kategori S2 (sesuai bersyarat) untuk dijadikan pencadangan kawasan konservasi lamun. 


\section{SIMPULAN}

Hasil penelitian di Perairan Beloreng dapat disimpulkan sebagai berikut: Potensi lamun di Perairan Beloreng ditemukan 5 jenis lamun yaitu Enhalus acoroides, Thalassia hemprichii, Cymodeca serrulata, Halodule uninervis, dan Halophila decipiens, tingkat kerapatan lamun tergolong rendah/jarang. Di Perairan Beloreng terdapat 7 jenis biota yang dijumpai diantaranya kepiting rajungan (Portunus pelagicus.), kerang kampak (Atrina pectinata), siput gonggong (Strombus turturella), ikan baronang (Siganus sp.), teripang jepun (Stichopus chloramatus), dugong (Dugong dugon) dan ular (Bungarus fasciatus). Tingkat kesesuaian sumberdaya lamun dilihat dari aspek ekologi, sosial dan budaya tergolong dalam kategori S2 (sesuai bersyarat) untuk dijadikan pencadangan kawasan konservasi lamun.

\section{UCAPAN TERIMA KASIH}

Penulis mengucapkan terimakasih kepada kedua organg tua dan keluarga serta semua pihak yang telah memberikan masukan dan bimbingan dalam menyelesaikan skripsi ini, Dr. Febrianti Lestari, S.Si., M.Si. selaku pembimbing utama dan Susiana, S.Pi., M.Si. selaku pembimbing pendamping, Dedy Kurniawan, S.Pi., M.Si. selaku ketua penguji dan Dr. Ani Suryanti, S.Pi., M.Si. selaku anggota penguji yang telah banyak memberikan kritik dan saran dalam penyelesaian Skripsi ini. Semoga karya ilmiah ini bermanfaat.

\section{REFERENSI}

Azkab, M.H. (2000). Produktivitas di Lamun. Jurnal Oseana, 25 (1): 13-22.

Badan Perencanaan Pembangunan Daerah Kabupaten Bintan. (2010). Potensi Ekosistem Penting dan Kondisi Hidrologisnya di Wilayah Bintan Bagian Timur. Kabupaten Bintan.

Gosari, J.A., \& Haris, A. (2012). Studi Kerapatan dan Penutupan Jenis Lamun di Kepulauan Spermonde. Torani:Jurnal Ilmu Kelautan dan Perikanan, 22(3): 256-162.

Hardiyanti, S., Umar, M.R., \& Priosambodo, D. (2011). Analisis Vegetasi Lamun di Perairan Pantai Mara Bombang Kabupaten Pinrang. E-Journal FMIPA. Universitas Hasanuddin. Makasar.

Kementerian Kelautan Perikanan. (2013). Data dan Informasi Kriteria Pertimbangan dan Penentuan Dealinasi Serta Pengaturan Kawasan Konservasi dalam RZWP3K. Jakarta.

Keputusan Menteri Negara Lingkungan Hidup Nomor 200 Tahun 2004 Tentang Kriteria Baku Kerusakan dan Pedoman Penelitian Status Padang Lamun.

Krebs, C.J. (1985). Ecology. The Experimental Analysis Of Distribution And Abundance. Third Edition. Harper And Row Publisher Inc. New York.

Kuo, J. (2007). New Monoecious Seagrass of Halophila sulawesii (Hydrocharitaceae) from Indonesia. Aquatic Botany, 87: 171-175.

Purba, R.R., Lestari, F., \& Kurniawan, D. (2018). Hubungan Kerapatan Lamun dengan Kelimpahan Gastropoda di Perairan Tanah Merah Desa Penaga Kabupaten Bintan. Repository UMRAH.

Purnomo, H.K., Yusniawati, Y., Putrika, A., Handayani, W., \& Yasman. (2017). Seagrass species diversity at various seagrass bed ecosystems in the West Bali National Park Area. Jurnal Prosiding Seminar Nasional Masyarakat Biodiversitas Indonesia, 3(2): 236-240.

Raharja, S. (2008). Studi Empiris Mengenai Penerapan Metode Sampling Audit dan Faktorfaktor yang Mempengaruhi Penggunaan Metode Sampling Audit Oleh Auditor Bpk. Jurnal Bisnis dan Ekonomi, 15(1): 54-66.

Rahmawati, S., Indarto, H.S., Azkab, M.H., \& Kiswara, W. (2014). Panduan Monitoring Padang Lamun. Coremap CTI LIPI. Jakarta.

Sari, D.P., Lestari, F., \& Kurniawan, D. (2018). Hubungan Kerapatan Lamun Dengan Kepadatan Bivalvia di Perairan Desa Pengudang. Repository UMRAH.

Syukur, A. (2015). Distribusi, Keragaman Jenis Lamun (Seagrass) dan Status Konservasi di Pulau Lombok. Jurnal Biologi Tropis, 15(2): $171-182$.

Syukur, A. (2016). Konservasi Lamun untuk Keberlanjutan Sumberdaya Ikan di Perairan Pesisir Indonesia. Jurnal Biologi Tropis, 16(1): 56-65.

Wagey, B.T., \& Sake, W. (2013). Variasi Morfometrik Beberapa Jenis Lamun di Perairan Kelurahan Tongkeina Kecamatan Bunaken. Jurnal Pesisir dan Laut Tropis, 3(1): 36-44.

Yulianda, F., (2007). Ekowisata Bahari sebagai Alternatif Pemanfaatan Sumberdaya Pesisir Berbasis Konservasi. Makalah. Departemen Manajemen Sumberdaya Perairan. Faultas Perikanan dan Ilmu Kelautan. Institut Pertanian Bogor. Bogor. 